\title{
A QUARTA FASE DA DISSOLUÇÃO SOCIETÁRIA
}

\author{
FOURTH PHASE OF CORPORATE DISSOLUTION
}

\section{Vinícius José Marques Gontijo* Gustavo Rezende*}

\begin{abstract}
Resumo
A extinção de uma pessoa jurídica é o resultado de um procedimento de dissolução societária, capitaneada por teoria dissolutória que perpassa o sistema legal brasileiro, este procedimento é compreendido por quatro etapas (ou fases), a saber: $a$ ) dissolução, $b$ ) liquidação, $c$ ) extinção e $d$ ) exigibilidade de obrigações após a extinção da sociedade. A quarta etapa foi inicialmente desvendada por pesquisas realizadas por Fran Martins, sendo que, no entanto, grande parte da doutrina brasileira até hoje discorda da existência desta última etapa. Dessa feita, neste nosso articulado, investigamos a compreensão técnica de cada uma das fases/etapas do procedimento de dissolução para, ao final, analisar a figura técnica da quarta fase tendo por paradigma a Lei de Falências (Lei n. 11.101/2005). A partir do nosso estudo, com emprego da metodologia jus-positivista dogmática kelseniana, é possível demonstrar de maneira precisa e insofismável a conclusão técnica da existência jurídica desta quarta fase, que é fundamental na compreensão completa do instituto jurídico da dissolução-procedimento. Naturalmente, não olvidamos as divergências havidas sobre o tema, bem como a necessidade de alocar pesquisas acerca das consequências teóricas e práticas da conclusão da existência da quarta fase na dissolução-procedimento, ou seja a exigibilidade de obrigações mesmo após a "baixa" da pessoa jurídica no órgão do registro competente.
\end{abstract}

Palavras-chave: Dissolução. Liquidação. Extinção da pessoa jurídica. Falência.

\begin{abstract}
The extinction of a legal entity is the result of a corporate dissolution procedure, led by dissolutory theory that permeates the Brazilian legal system, this procedure is comprised of four stages (or phases), namely: a) dissolution, b) liquidation, c) extinction and d) enforceability of obligations after the extinction of the company. The fourth stage was initially unveiled by research carried out by Fran Martins, although, however, much of the Brazilian doctrine to date disagrees with the
\end{abstract}

Artigo submetido em 15 de julho de 2020 e aprovado em 17 de agosto de 2020.

\footnotetext{
* Doutor em Direito Comercial pela UFMG. Mestre em Direito Comercial pela UFMG. Professor no Curso de Mestrado em Direito das Relações Econômicas e Sociais, Estado Democrático de Direito e Políticas Públicas da Faculdade de Direito Milton Campos. Professor no Curso de Graduação em Direito da Faculdade de Direito Milton Campos. Professor no Curso de Graduação em Direito da PUC/MG. Ex-Professor de Graduação da UFMG e UFOP. Belo Horizonte - MG - Brasil. Advogado. E-mail: vinicius@ viniciusgontijo.com.br

** Mestrando em Direito das Relações Econômicas e Sociais, Estado Democrático de Direito e Políticas Públicas da Faculdade de Direito Milton Campos. Pós-Graduação lato sensu em Direito Tributário. Belo Horizonte - MG - Brasil. Advogado. E-mail: gustavo0rezende@outlook.com
} 
existence of this last stage. This time, in this article, we investigated the technical understanding of each of the phases / stages of the dissolution procedure in order, at the end, to analyze the technical figure of the fourth phase using the Bankruptcy Law as a paradigm (Law No. 11,101 / 2005). From our study, using the dogmatic Kelsenian jus-positivist methodology, it is possible to demonstrate in a precise and unquestionable way the technical conclusion of the legal existence of this fourth phase, which is fundamental in the complete understanding of the legal institution of the dissolution-procedure. Naturally, we do not forget the disagreements on the subject, as well as the need to allocate research on the theoretical and practical consequences of the conclusion of the existence of the fourth phase in the dissolution-procedure, that is, the requirement of obligations even after the person's "retirement". in the competent registry body.

Keywords: Dissolution. Liquidation. Extinction of the legal entity. Bankruptcy.

\section{INTRODUÇÃO}

A dissolução de sociedade é abarcada por grande parte da doutrina como um procedimento contendo três fases, que se compreende pela dissolução como causa/efeito, a liquidação e a extinção. Contudo, Fran Martins afirmava que mesmo após a extinção da pessoa jurídica ainda subiste um período de obrigações e que por isso a pessoa jurídica não estaria completamente extinta.

O presente articulado irá adotar uma metodologia analítica de cada uma das fases do procedimento de dissolução, investigando a doutrina de Fran Martins como marco teórico, buscando comprovar a sua teoria por meio de uma metodologia kelsiana juspositivista.

Nesta toada, o presente estudo inicia-se detalhando a primeira fase do procedimento de dissolução de sociedade, diferenciando a dissolução sentido strictu sensu do sentido lato sensu, que são, respectivamente, entendidos como ato e procedimento. Posteriormente, entrase na segunda fase do procedimento dissolutório, qual seja: a liquidação, que também se diferencia entre o seu estado e o seu procedimento, o estado de liquidação é quando a pessoa jurídica já é considerada dissolvida, mas mantém a personalidade jurídica apenas para liquidar o acervo social; a liquidação como procedimento necessita ser iniciada e consubstancia basicamente uma série de ações para realizar o ativo da sociedade, pagar o passivo e ratear o remanescente, se houver, entre os sócios. E, por fim, chegamos à terceira fase, que é a extinção da sociedade, sendo necessário, neste ponto, compreender a ideia de que o nascedouro e a extinção da personalidade jurídica se dão com o registro no órgão competente, 
sendo que para grande parte da doutrina, conforme demonstraremos, esta fase culmina no término do procedimento de dissolução.

Contudo, transcorridas todas estas três fases do procedimento dissolutório, investigaremos a hipótese trazida por Fran Martins, que se dá basicamente quando voltamos as pesquisas para o inciso VIII do art. 96 da Lei n. 11.101/2005, em que prevê a hipótese de a pessoa jurídica extinta ter sua falência decretada. De fato, os argumentos do doutrinador atiçam a curiosidade científica, na medida em que, mesmo após a extinção da pessoa jurídica, ela responde por obrigações que não foram resolvidas com o cancelamento de seu registro. Assim, investigaremos a existência, ou não, desta quarta fase que, eventualmente, compõe a dissolução-procedimento.

\title{
2 A DISSOLUÇÃO DE SOCIEDADE
}

Dissolução de sociedade pode ser entendida em sentido stricto e em sentido lato. No sentido técnico, strictu, pode ser entendida como causas enumeradas por lei que não determinam a extinção da pessoa jurídica, ${ }^{1}$ sendo que ocorre na verdade a mudança no status da sociedade, em que ela para de explorar a empresa com fim lucrativo e passa a realizar atos direcionados a encerrar a atividade empresarial.

Em sentido lato o termo dissolução é utilizado para representar as fases em que a sociedade será submetida, até se chegar a sua extinção de fato. Basicamente, a maioria da doutrina entende que a dissolução-procedimento é formada por três fases, sendo elas: dissolução (causa-efeito), a liquidação e a extinção da pessoa jurídica. ${ }^{2}$ Fran Martins assim discorre sobre estas três fases:

\begin{abstract}
A extinção das sociedades empresárias compreende períodos distintos: um período e que se paralisam todas as atividades externas da sociedade, a que se da comumente o nome de dissolução; um período em que a sociedade realiza o seu ativo e liquida o passivo, ou seja, transforma todo o seu patrimônio em dinheiro e satisfaz os compromissos assumidos, a que se da o nome de liquidação. [...] Deverá, assim, para se extinguir, em primeiro lugar, a sociedade transformar todo o seu ativo em dinheiro, ou seja, realizar esse ativo e solver os compromissos assumidos. Depois de satisfeitos esses requisitos e arquivados o documentos relativos à liquidação no
\end{abstract}

\footnotetext{
${ }_{1}^{1}$ PENTEAdO, Mauro Rodrigues, Dissolução e Liquidação de Sociedade. 2. ed. São Paulo: Saraiva 2000, p. 17.

2 "Fala-se em dissolução lato sensu da sociedade, para se definir a série de eventos pelos quais deve passar a pessoa jurídica em vias de se extinguir, tenha ela origem contratual ou institucional. Entretanto, o que há na realidade é um conjunto de atos complexos, tradicionalmente divisível em três fases distintas: a dissolução, a liquidação e a extinção.” (BARBI FILHO, Celso. Dissolução Parcial de Sociedades Limitadas. Belo Horizonte: Mandamentos, 2004. p. 109.
} 
Registro Público de Empresas Mercantis e Atividades Afins é, na verdade, a sociedade se extinguirá, deixando de ser sujeito de direito. ${ }^{3}$

Assim, a dissolução pode ser entendida como uma causa/efeito que se realiza de "pleno direito" quando deriva de alguma hipótese prevista em lei ou por conta de alguma estipulação contratual que, se contestada, venha a ser judicialmente apurada. Deste modo, operada alguma das hipóteses, a consecução de obtenção de lucros através da empresa é interrompida, alterando o status de funcionamento da sociedade, que ingressará no estado de liquidação. Portanto, para ocorrer a dissolução é preciso que exista uma causa anterior a sua declaração e, ao ser constatada, acaba gerando a resilição, resolução ou rescisão do contrato.

É certo que não há como declarar a dissolução sem a existência de causa pretérita, pois dissolução é o efeito da ocorrência de alguma causa legal ou contratual. Uma vez atingida alguma dessas hipóteses, a sociedade entrará no procedimento de dissolução e consequentemente passará para sua segunda fase, entendida como liquidação.

Assim, dissolução é um acontecimento que a lei reputa determinante para se iniciar o procedimento que culmina na extinção da pessoa jurídica, de modo que, para a sociedade ser extinta, "desapareça" do mundo jurídico, é preciso, normalmente, que ela entre em estado de liquidação seguido do procedimento de liquidação, a fim de que sejam concluídos os negócios pendentes, convertidos em dinheiro os bens e direitos que compõem o patrimônio social, pagas dívidas e divididas as eventuais sobras entres os sócios. ${ }^{4}$

Independentemente, do Diploma Legal que se investigue no Brasil, pode-se constatar a existência da teoria das fases que compõem a dissolução-procedimento das sociedades como vetor hermenêutico.

Assim, mudando o eixo de investigação, mas coerente com a metodologia empregada neste trabalho, o art. 207 da Lei n. 6.404/1976 (Lei das Sociedades Anônimas) determina que a companhia dissolvida conserve a personalidade jurídica, até a extinção, com o fim de proceder à liquidação. ${ }^{5}$ É nítida a separação feita entre as fases (ou etapas) do procedimento de dissolução, de modo que a sociedade é considerada dissolvida independentemente do início do procedimento de liquidação. Portanto, a sociedade e a personalidade jurídica que a ela atribuída se mantêm apenas com suspensão de suas atividades operacionais normais, voltando sua finalidade para a prática de atos necessários à liquidação do patrimônio societário. ${ }^{6}$

\footnotetext{
3 MARTINS, Fran. Comentários à Lei de Sociedades Anônimas. 4. ed., Rio de Janeiro: Forense, 2010, p. 190.

${ }^{4}$ GONÇALVES NETO, Alfredo de Assis. Direito de Empresa. São Paulo: Revista dos Tribunais. 2007, p. 259.

${ }_{6}^{5}$ De maneira semelhante para as sociedades contratuais, tem-se prescrito no art. 51 do Código Civil.

${ }^{6}$ MARTINS, Fran. Comentários à Lei de Sociedades Anônimas. 4. ed., Rio de Janeiro: Forense, 2010, p. 868.
} 
A Lei das Sociedades Anônimas (LSA), em seu artigo 206, enumera diversas hipóteses de dissolução, sendo divididas entre as causas de pleno direito, que são aquelas que carecem de uma decisão judicial ou administrativa para implicar dissolução da companhia, a judicial e a hipótese de dissolução por decisão administrativa.

Coerente com a teoria da dissolução, o Código Civil, em seu art. 1.033, elenca cinco hipóteses de dissolução, que se aplicam para as sociedades regidas por aquele Diploma, que se somam à aquelas judicias prescritas pelo art. 1.044 do mesmo Código.

Não se perca ainda de vista, que a dissolução compulsória abarcada pela Lei $\mathrm{n}$. 12.846/2013 pode ser considerada exemplo de dissolução administrativa.

Portanto, deve-se compreender a dissolução como um procedimento constituído de diferentes fases, que culminará com a extinção da sociedade, sendo a própria dissolução considerada como a primeira fase do procedimento dissolutório, fase esta que tem natureza declaratória. Com isso, a sociedade é considerada dissolvida, alterando o status de funcionamento da sociedade, que se destinará a extinguir as relações jurídicas existentes e ratear entre os sócios o patrimônio remanescente, caso venha a existir ao final do procedimento de dissolução.

\section{PROCEDIMENTO DE LIQUIDAÇÃO}

O procedimento de liquidação pode ser entendido como conjunto de atos sucessivos predeterminados em lei e, subsidiariamente, no contrato ou estatuto social, aos quais ficará estritamente vinculado o liquidante no exercício de suas funções legalmente estabelecidas. ${ }^{7} \mathrm{O}$ objetivo da liquidação é encerrar as relações jurídicas assumidas pela pessoa jurídica antes da declaração da dissolução, a fim de realizar o ativo da sociedade, pagando-se o passivo e distribuindo entre os sócios o eventual acervo remanescente.

Conforme dissemos, a expressão técnica liquidação se compreende de duas maneiras distintas, existe o estado de liquidação e o procedimento de liquidação. ${ }^{8} \mathrm{O}$ estado de liquidação corresponde a mudança no status da pessoa jurídica, em que ela altera suas atividades, é o momento posterior ao ato dissolutório, tanto que o próprio artigo 207 da Lei n. 6.404/1976, assim como o art. 51 do Código Civil, prescreve que a sociedade dissolvida

\footnotetext{
${ }^{7}$ CARVAlHOSA, Modesto. Comentários ao Código Civil. São Paulo: Saraiva. 2003. v. 13. p. 443.

${ }^{8}$ PENTEADO, Mauro Rodrigues, Dissolução e Liquidação de Sociedade. 2. ed., São Paulo: Saraiva 2000, p. 73.
} 
mantém a personalidade jurídica somente para proceder com a liquidação. Opera-se, assim, uma alteração de estado, antes mesmo do início do procedimento de liquidação. ${ }^{9}$

A alteração do status da companhia resulta no estado de liquidação; os administradores que irão representar a sociedade durante o estado de liquidação devem ter em mente que a pessoa jurídica estará se preparando para ingressar no procedimento de liquidação, que será instaurado nos termos do art. 208 e 209 da Lei de S.A. ${ }^{10}$ Carnelutti leciona o seguinte sobre a mudança de estado da companhia:

\begin{abstract}
a diversidade do seu efeito em relação ao da extinção da pessoa física cifra-se em que, podendo a dissolução de um grupo, ao contrário da morte de um homem, ser disciplinada, a sucessão faz-se proceder de uma mudança de estado, mediante o instituto da liquidação. A liquidação consiste justamente numa mudança de estado, que tem por fim preparar a sucessão do patrimônio líquido, e não no patrimônio bruto, como acontece na extinção da pessoa física. Nessa combinação entre os dois institutos de mudança de estado e de liquidação, em que se poderá dizer que, em regra, se faz morrer por graus a pessoa jurídica, é que, a querer ter em conta a teoria geral, deverá ser assente uma teoria da liquidação. ${ }^{1}$
\end{abstract}

Interessante notar que, nas palavras do doutrinador italiano, a mudança de estado na sociedade implica ir "matando aos poucos" a pessoa jurídica, de modo que cada estágio do procedimento de dissolução prepara a sociedade para o seu derradeiro fim, que se consubstancia com a extinção.

Contudo, essa "morte em graus" abordada não se dá apenas pela mudança de status da sociedade, uma vez que, consumado o estado de liquidação, é necessário ingressar no procedimento de liquidação, conforme disposto nos artigos 208 e 209 da Lei n. 6.404/1976, que, caso a assembleia geral, ou o conselho de administração, não inicie o procedimento de liquidação, poderá qualquer acionista requerer em juízo que se inicie a liquidação ou o próprio Ministério Público poderá fazê-lo, conforme disposto no inciso II do art. 209 da LSA.

A alteração no estado da sociedade não significa uma alteração no objeto social da companhia, mas sim no seu escopo. A sociedade não irá mais atuar visando à sua continuidade operacional além da vida humana ${ }^{12}$, mas visará à sua liquidação e, finalmente, à sua extinção, tanto que o art. 211 da LSA impõe ao liquidante a prática de todos os atos necessários para a liquidação, sendo vedado contrair empréstimos ou gravar bens sem a

\footnotetext{
${ }^{9}$ PENTEADO, Mauro Rodrigues, Dissolução e Liquidação de Sociedade. 2. ed., São Paulo: Saraiva 2000, p. 18.

${ }^{10}$ No mesmo sentido, confronte os arts. 1.102 a 1.112 do Código Civil.

${ }^{11}$ CARNELUTTI, Francesco. Teoria Geral do Direito. Trad. Port. São Paulo. Livr. Acadêmica Saraiva, 1942. p. 322.

${ }^{12}$ MARTINS, Fran. Comentários à Lei de Sociedades Anônimas. 4. ed., Rio de Janeiro: Forense, 2010, p. 870. O autor afirma que "as sociedades anônimas normalmente têm existência superior à da vida humana".
} 
expressa autorização da assembleia geral de acionistas, salvo se tais atos forem indispensáveis para pagamento de obrigações inadiáveis, conforme disposto no parágrafo único do próprio artigo mencionado.

O procedimento de liquidação necessita ser iniciado, não sendo normalmente um procedimento que acontece automaticamente com dissolução; pela Lei de Sociedades Anônimas, a liquidação pode ser judicial (art. 209) ou ser realizada pelos órgãos da companhia (art. 208), casos em que necessariamente será nomeado um liquidante para inaugurar o procedimento. De maneira semelhante, observa-se no procedimento administrativo, como, por exemplo, aquele decorrente da Lei n. 6.024/1974 (Lei de Intervenção e Liquidação Extrajudicial - LILE).

O procedimento de liquidação abordado pelo Código Civil, também segue a mesma linha principiológica e, dessa feita, nos termos do disposto no art. 1.102, necessita ser iniciado após a sociedade ser dissolvida, deve-se nomear um liquidante para proceder com a liquidação.

A liquidação (procedimento) é a fase responsável por promover os atos extintivos das obrigações da sociedade e das relações jurídicas daí decorrentes, realizando o ativo e satisfazendo o passivo exigível. Iniciado esse procedimento, o liquidante, nos moldes da Lei n. 6.404/1976, pode ser aquele nomeado previamente pelo estatuto social ou, será eleito pela assembleia-geral de acionistas ou ainda pelo conselho de administração, se este estiver em funcionamento, e, em alguns casos, serão eleitos judicialmente. Nos casos abordados pelo Código Civil, o liquidante pode ser ou não o administrador da sociedade (art. 1.102), existindo, também, a hipótese de liquidação judicial (artigos 1.111 e 1.112).

O liquidante será, então, o órgão da pessoa jurídica que, durante o intervalo de tempo da fase de liquidação e de extinção, pratica os atos destinados ao fim da sociedade.

Durante todo este período, perdura a personalidade jurídica, sendo que a sociedade continua a empregar o mesmo nome empresarial - firma ou denominação -, acrescido, porém, da expressão - "em liquidação".

Esse nome social será utilizado pelo liquidante todas as vezes que tiver de assinar como o órgão da sociedade, que a representa, sendo que a responsabilidade do liquidante decorre dos atos praticados e dos encargos assumidos, durante seu período de gestão, prestando contas e atendendo qualquer solicitação, seja a requerimento do juízo, da sociedade, 
ou de algum órgão da própria sociedade liquidanda. ${ }^{13}$ Ambas as legislações (Código Civil e Lei das SA) determinam a convocação de uma assembleia, após o pagamento do passivo e rateado o ativo remanescente, para que o liquidante preste as contas e, caso aprovada, encerrase a liquidação.

Portanto, é preciso clareza acerca da diferença entre as denominações de "estado de liquidação" e de "procedimento de liquidação", uma vez que o primeiro refere-se à mudança de status da sociedade, enquanto que o último necessita ser iniciado e compreende uma conjunto de atos, previstos em lei ou contratualmente, visando à realização do ativo e ao pagamento do passivo exigível, com a partilha do acervo remanescente entre os sócios, se houver.

\section{A EXTINÇÃo SOCIETÁRIA.}

Ultrapassadas as fases de dissolução e liquidação, passamos a analisar a terceira fase, qual seja: a da extinção. A sistemática estabelecida pelo Código Civil dá a entender que a extinção da sociedade termina com a sua dissolução-procedimento. No entanto, a extinção deve ser considerada como uma das fases do procedimento dissolutório, sendo que parte da doutrina entende a extinção como a última fase do procedimento de dissolução. ${ }^{14}$

Nas palavras de Mauro Rodrigues Penteado a extinção representa a conjugação e a conclusão de uma série de atos e negócios jurídicos legalmente previstos para se que ponha termo à sociedade, ao contrato/estatuto social e à própria personalidade jurídica ${ }^{15}$.

As sociedades são constituídas através de instrumentos plurilaterais, que podem ser os contratos ou estatutos sociais.

Constituídas a partir de um contrato ou estatuto, este não irá ser extinto quando atingido o seu objeto. Ao revés, o instrumento societário de uma sociedade regula os interesses das "partes", que resulta na criação de uma terceira pessoa para atuar em um determinado meio com o fim de atingir um objeto previamente traçado pelas partes, na execução deste instrumento societário, eles continuarão buscando o objetivo comum, que é o lucro para as sociedades empresárias, de maneira consecutiva ao longo do tempo.

\footnotetext{
${ }^{13}$ MARTINS, Fran. Comentários à Lei de Sociedades Anônimas. 4. ed., Rio de Janeiro: Forense, 2010, p..275.

${ }^{14}$ MARTINS, Fran, Curso de Direito Comercial. 29. ed, Rio de Janeiro: Forense, 2005, p.190.

${ }^{15}$ PENTEADO, Mauro Rodrigues, Dissolução e Liquidação de Sociedade. 2. ed. São Paulo: Saraiva 2000, p. 55.
} 
Portanto, os instrumentos constitutivos de uma sociedade (contrato social e estatuto social) se enquadram em uma subespécie dos "contratos", denominada de "contrato plurilateral". Tullio Ascarelli assim leciona:

\begin{abstract}
De outro lado, no entanto, a constituição de uma sociedade represente apenas um primeiro passo: a sociedade, uma vez constituída, visa a uma finalidade comum a todos os sócios, todos interessados na melhor realização dela; constitui um instrumento que, uma vez constituído, favorece a todos os sócios.

Por conseguinte, oposição de interesses, na constituição da sociedade; coincidência, porém, no que concerne à realização daquela comum finalidade social, que redunda em proveito de todos os sócios, embora em medida diversa, o que, por sua vez, explica o contraste na constituição; embora sem excluir, portanto, um real conflito de interesses, também durante a vida da sociedade. ${ }^{16}$
\end{abstract}

Prosseguindo, com o registro dos atos constitutivos no órgão competente ocorre o "nascimento" de direito da sociedade, em outras palavras, é com o registro que a sociedade adquire a personalidade jurídica. A constituição e a extinção somente se operam de maneira eficaz perante terceiros a partir do arquivamento válido, não ocorrendo o registro, a relação existente entre as partes se torna uma situação de fato e eficaz entre elas, mas não são passíveis de serem oponíveis a terceiros.

\begin{abstract}
Enquanto não for feito esse cancelamento, a pessoa jurídica, apesar de já haver a sociedade liquidado o seu patrimônio, pagando todas as dívidas sociais e, antecipando-se à extinção, rateado o remanescente entre os acionistas, ainda tem nome próprio, domicilio, nacionalidade, e em principio continuam os seus administradores responsáveis subsidiariamente, inclusive para com o fisco, pelos ônus que vierem a passar a sociedade que já não mais funciona. E havendo Cadastro Nacional das Pessoas Jurídicas, em que a sociedade esteja inscrita, só será dada baixa da mesma nesse Cadastro depois de se verificar no Registro do Comércio o cancelamento do registro da companhia. ${ }^{17}$
\end{abstract}

No caso de uma sociedade anônima, a extinção da sociedade ocorre com o arquivamento dos documentos concernentes à liquidação, cancelando-se então o registro da pessoa jurídica, não se extinguindo, portanto, com o mero encerramento da liquidação, conforme dispõem o $§ 1^{\circ}$ do art. 216 e o inciso I do art. 219 da Lei 6.404/1976. ${ }^{18}$ A Lei de S.A prevê, ainda, hipóteses de extinção da sociedade com a incorporação, fusão e cisão total.

\footnotetext{
${ }^{16}$ ASCARELLI, Tullio. Problemas das Sociedades Anônimas e Direito Comparado. 1. ed., Campinas: Bookseller, 2001, p. 374.

${ }^{17}$ MARTINS, Fran. Comentários à Lei de Sociedades Anônimas. 4ªed., Rio de Janeiro: Forense, 2010, p. 916.

${ }^{18}$ MARTINS, Fran. Comentários à Lei de Sociedades Anônimas. 4. ed., Rio de Janeiro: Forense, 2010 , p. 915.
} 
Em contrapartida, o Código Civil, em seu art. 1.109, diferentemente da Lei das S.A, dispõe que a extinção da sociedade se dá com averbação, no registro próprio, da ata da assembleia que aprovou as contas da liquidação.

Assim, podemos entender a extinção como a culminação de uma série de fatores, como parte de uma etapa do procedimento de dissolução, que começa com a própria dissolução ato/fato, passa-se pela liquidação e termina com a extinção da pessoa jurídica, sendo certo que a extinção da sociedade se dá com a baixa do registro junto ao órgão competente em que foi registrada.

O conceito de extinção de sociedade não deve ser entendido de maneira isolada, pois, conforme vimos, a extinção é uma fase do procedimento de dissolução, em que, normalmente, para se chegar até esta é necessário percorrer por outras etapas e ao ser atingida a etapa da extinção, que se aperfeiçoa com o arquivamento dos documentos concernentes à liquidação no órgão competente, o efeito resultante disto é o cancelamento ("baixa") do registro da pessoa jurídica.

Portanto, a previsão legal trazida pelo Código Civil possui um rigor técnico melhor do que aquela prevista pela Lei de Sociedades Anônimas, não sendo razoável entender que a extinção da personalidade se daria meramente com o ato de aprovação das contas e o rateio do remanescente entre os sócios.

\section{A QUARTA FASE DA DISSOLUÇÃO: OS DIREITO E OBRIGAÇÕES APÓS A EXTINÇÃO}

Com vimos, grande parte da doutrina compreende que a dissolução-procedimento possui apenas três fases, a primeira, que se inicia com a dissolução, a segunda, na qual se passa para a liquidação e, finalmente, a terceira, que termina com a extinção da pessoa jurídica.

Contudo, preciso e com acurada percepção, Fran Martins alertava para outra fase, portando, uma quarta fase, existente após a extinção da pessoa jurídica, que corresponde aos direitos e obrigação reclamados depois de extinta a pessoa jurídica, vejamos o que afirma o autor:

Na técnica do revogado art. 352 do Código Comercial, os livros deveriam ser guardados e conservados, mesmo depois de liquidada e feita a partilha definitiva da sociedade. A expressão guarda sintonia com o art. 1.194 do Código Civil, ao determinar a boa guarda enquanto não houver prescrição ou decadência no tocante aos atos neles consignados. Nesse sentido também se manifestou a jurisprudência, 
através de uma sentença famosa do juiz Macedo Soares, proferida em 8 de março de 1888, que declara que a guarda dos livros e dos documentos dos comerciantes, uma vez extinta a sociedade, tem por finalidade "pô-los ao alcance e disposição de quem neles tenha necessidade de verificar direitos que lhe compitam ou obrigações que lhe incubam". Ora, esses direitos e obrigações serão reclamados depois de extinta a pessoa jurídica, já que a extinção se verifica com a integral liquidação do patrimônio social. Se, porém, tais direitos e obrigações podem ser reclamados depois da dissolução da sociedade, é evidente que a pessoa jurídica não desapareceu completamente. As ações que porventura sejam movidas contra ex-sócios o serão em função da sua antiga qualidade, o que demonstra que a pessoa jurídica não se extingue com a dissolução da sociedade, mas apenas quando prescreverem todas as ações que contra a mesma possam ser intentadas. Só aí, realmente, a pessoa jurídica está inteiramente livre de compromissos; a dissolução, assim, marca apenas a cessação definitiva das atividades sociais. ${ }^{19}$

A obrigação dos sócios de responder pelas dívidas da pessoa jurídica decorre de previsão legal, mais especificamente do artigo 1.110 do CC e do art. 218 da LSA. Observe-se que o autor enfatiza o fato de que se sócios responderem por obrigações derivadas da pessoa jurídica, é porque a pessoa jurídica ainda existe. Logo, se a pessoa jurídica estivesse de fato extinta, a qualidade de ex-sócio também teria desaparecido do meio jurídico, não havendo que se falar, portanto, em ações movidas contra ex-sócios, pois, se não existe a pessoa jurídica, não há que se falar em vínculo com a pessoa jurídica.

Fato é que os ex-sócios podem ser acionados por eventuais ações decorrentes de direitos e obrigações que seriam da sociedade e que perdurarem mesmo após a extinção da personalidade jurídica. Portanto, a pessoa jurídica não "desaparece” completamente com a conclusão da fase de extinção, uma vez que os ex-sócios ainda continuam vinculados às obrigações acaso ainda existentes e que, a priori, seriam de atribuídas à sociedade, até que se prescrevam todas as ações que contra ela possam ser intentadas. Fábio Ulhoa Coelho argumenta o seguinte sobre a hipótese de Fran Martins:

Fran Martins defende que ainda há uma derradeira fase no procedimento extintivo, consistente no decurso do prazo prescricional das obrigações da sociedade dissolvida. Entende a maioria da doutrina, contudo, que essa lição não seria de todo acertada. Se a liquidação não foi completa e regular a ponto de restar pendente uma ou mais obrigações, isto não é ato imputável à sociedade, mas aos sócios e ao liquidante, que responderão, pessoalmente, pelos atos da liquidação irregularmente feita. $^{20}$

Contudo, devemos discordar do que pensa a maioria da doutrina. Para tanto, a fim de comprovar a hipótese proposta por Fran Martins, necessitamos voltar os olhos para o inciso

\footnotetext{
${ }^{19}$ MARTINS, Fran, Curso de Direito Comercial. 29. ed, Rio de Janeiro: Forense, 2005, p. 191.

${ }^{20}$ COELHO, Fabio Ulhoa. Manual de Direito Comercial. 23. ed., 2. tiragem, São Paulo: Saraiva. 2011, p. 209.
} 
VIII do art. 96 da Lei n. 11.101/2005 (Lei de Falências e Recuperação de Empresas - LFRE), que assim dispõem:

Art. 96. A falência requerida com base no art. 94, inciso I do caput, desta Lei, não será decretada se o requerido provar:

Omissis.

VIII - cessação das atividades empresariais mais de 2 (dois) anos antes do pedido de falência, comprovada por documento hábil do Registro Público de Empresas, o qual não prevalecerá contra prova de exercício posterior ao ato registrado.

Percebe-se com isto que a falência requerida com base na hipótese de não pagamento de obrigação liquida que ultrapasse quarenta salários mínimos, não será decretada se for demonstrada que as atividades empresariais se encerraram mais de dois anos antes do pedido de falência.

Realizado todo o procedimento de dissolução, extinta a pessoa jurídica, com todos os atos devidamente registrados no Registro Público de Empresas, o credor poderá ainda requerer a falência do devedor pelos próximos dois anos, de modo que a personalidade jurídica não será mais considerada extinta e a falência da sociedade poderá ser decretada. Destarte, a personalidade de mantém latente durante este período legal e apta a recrudescer sua eficácia para fins falimentares e, em sendo o caso, reavocar para a massa falida o bens e direitos eventualmente partilhados com os sócios durante a fase de liquidação.

Portanto, mesmo após a sua extinção, a pessoa jurídica continua sujeita à Lei de Falências por dois anos a contar da data de registro dos atos que promoveram a extinção. Em outras palavras, a pessoa jurídica continua responsável por obrigações e direitos por dois anos após a sua extinção, com personalidade jurídica latente.

Observe-se que a Lei n. 11.101/2005 sequer transmite automaticamente aos sócios tais obrigações, vinculando-as a priori estritamente à pessoa jurídica, na medida em que, para que a falência não seja decretada, basta exibir os documentos arquivados no registro empresarial (verbi gratia o distrato social ou ato de encerramento da liquidação), portanto, é uma vinculação direta com atos concernentes e próprios da pessoa jurídica.

Em que pese grande parte da doutrina pontificar que a extinção da pessoa jurídica se dá com o registro do encerramento da liquidação no órgão competente, é necessário atentar a hipótese prevista pela Lei de Falências, pois resta comprovado que a existência da pessoa jurídica perdura por dois anos após a sua extinção, tanto é assim, que, caso existam obrigações inadimplidas que correspondam a mais de quarenta salários mínimos protestadas, a pessoa jurídica poderá vir à bancarrota. 
Por outras palavras, a fase de extinção não fulmina, não extingue, de fato, a pessoa jurídica. As obrigações que existiam em nome da sociedade persistem por um lapso temporal, tanto que a sociedade pode vir a sofrer as consequências da falência pelos próximos dois anos subsequentes à baixa registral.

\section{CONCLUSÃO}

A maioria da doutrina não admite a existência da quarta fase da dissoluçãoprocedimento, que compreende a extinção das obrigações sociais após a própria extinção da pessoa jurídica. Porém a Lei de Falências prescreveu a possibilidade de se decretar a falência de uma sociedade mesmo que já se tenham realizados todos os atos registrais para se proceder com o cancelamento da personalidade jurídica.

Aberta esta possibilidade pela Lei de Falências, resta nítido que a pessoa jurídica ainda é responsável direta pelas obrigações e direitos assumidos com terceiros, enquanto ainda era ativa. Sendo possível a bancarrota de uma sociedade já "extinta" seria, segundo entendemos, incoerente afirmar que a dissolução compreende-se por apenas três fases, pois a dissolução é mais do que encerrar uma empresa, é pôr fim às relações entre pessoas e, conforme vimos, tais obrigações podem perdurar mesmo após o término do ato de extinção da pessoa jurídica.

Finalmente, vale a reflexão, a ser investigada em artigo próprio, de até quando estas obrigações perduram; a Lei de Falências é expressa em estipular o prazo de dois anos, no entanto, se entendermos que o fato de os ex-sócios ainda continuarem vinculados por eventuais obrigações que eram da sociedade extinta, demonstra-se uma relação de existência de vínculo com aquela pessoa jurídica, então, o marco temporal de quando a sociedade será de fato e de direito extinta para todos os fins jurídicos deverá ser computado quando da prescrição das ações contra os ex-sócios se consumar.

Não interessa qual seria o prazo para que possamos concluir de maneira categórica acerca da existência da quarta fase na dissolução-procedimento.

Observe-se, então, que reconhecida a quarta fase da dissolução de sociedade, nos encontramos diante de uma nova questão, qual seja: o cômputo do prazo prescricional das obrigações dos (ex) sócios, na medida em que se pode compreender o prazo fixado pela Lei de Falências resulta em uma extinção do direito de ação para "responsabilizar" os antigos sócios por conta das obrigações que não foram adimplidas pela sociedade. Todavia, tal 
questão conflita com o disposto no Código Civil (artigo 206, §1 ${ }^{\circ}, \mathrm{V}$ ), haja a vista a diferença de prazos que cada lei fixa para a extinção das obrigações da pessoa jurídica.

Todavia, discorrer sobre tal assunto extrapola o tema delimitado pelo presente articulado, de modo que devemos nos debruçar sobre tal assunto em um artigo futuro focado estritamente na questão dos prazos prescricionais da sociedade após o término da fase de extinção, que é a terceira da dissolução-procedimento.

\section{REFERÊNCIAS}

ASCARELLI, Tullio. Problemas das Sociedades Anônimas e Direito Comparado. $1^{\text {a }}$ edição. Editora Bookseller. Campinas. 2000.

BARBI FILHO, Celso. Dissolução Parcial de Sociedades Limitadas. Belo Horizonte: Madamentos, 2004.

COELHO, Fabio Ulhoa. Manual de Direito Comercial. $23^{\mathrm{a}}$ ed., $2^{\mathrm{a}}$ tiragem. Editora Saraiva. São Paulo. 2011.

CARNELUTTI, Francesco. Teoria Geral do Direito. Trad. Port. Livr. Acadêmica Saraiva. São Paulo. 1942.

CARVAlHOSA, Modesto. Comentários ao Código Civil. Editora Saraiva, v. 13, São Paulo. 2003.

GONÇALVES NETO, Alfredo de Assis. Direito de Empresa. Editora Revista dos Tribunais. São Paulo. 2007.

MARTINS, Fran, Curso de Direito Comercial. 29. edição. Editora Forense. Rio de Janeiro, 2005 .

MARTINS, Fran. Comentários à Lei de Sociedades Anônimas. $4^{\mathrm{a}}$ edição. Editora Forense. Rio de Janeiro. 2010.

PENTEADO, Mauro Rodrigues, Dissolução e Liquidação de Sociedade. $2^{\mathrm{a}}$ edição. Editora. Saraiva. São Paulo. 2000. 